\title{
The biochemical and metabolic profiles of dairy cows with mycotoxins-contaminated diets
}

\author{
Qian Wang Equal frrst author, 1, 2, 3 , Yangdong Zhang ${ }^{\text {Equal first author, 1, 2, } 3}$, Nan Zheng ${ }^{1,2,3}$, Shengguo Zhao ${ }^{1,2,3}$, Songli Li ${ }^{1,2,3}$, Jiaqi \\ Wang Corresp. 1, 2, 3 \\ ${ }^{1}$ Chinese Academy of Agricultural Sciences, State Key Laboratory of Animal Nutrition, Institute of Animal Science, Beijing, People's Republic of China \\ 2 Chinese Academy of Agricultural Sciences, Key Laboratory of Quality \& Safety Control for Milk and Dairy Products of Ministry of Agriculture and Rural \\ Affairs, Institute of Animal Sciences, Beijing, People's Republic of China \\ ${ }^{3}$ Chinese Academy of Agricultural Sciences, Laboratory of Quality and Safety Risk Assessment for Dairy Products of Ministry of Agriculture and Rural \\ Affairs, Institute of Animal Sciences, Beijing, People's Republic of China
}

Corresponding Author: Jiaqi Wang

Email address: wangjiaqi@caas.cn

Background: Previous studies on the effects of mycotoxins have solely focused on their biochemical profiles or products in dairy ruminants. Changes in metabolism that occur after exposure to mycotoxins, as well as biochemical changes, have not been explored.

Methods: We measured the biochemical and metabolic changes in dairy cows after exposure to mycotoxins using biochemical analyses and nuclear magnetic resonance. Twenty-four dairy cows were randomly assigned to three different treatment groups. Control cows received diets with $2 \mathrm{~kg}$ uncontaminated cottonseed. Cows in the $50 \%$ replacement group received the same diet as the control group, but with $1 \mathrm{~kg}$ of uncontaminated cottonseed and $1 \mathrm{~kg}$ of cottonseed contaminated with mycotoxins. Cows in the $100 \%$ replacement group received the same diet as the control, but with $2 \mathrm{~kg}$ contaminated cottonseed.

Results: The results showed that serum $y$-glutamyl transpeptidase and total antioxidant capacities were significantly affected by cottonseed contaminated with mycotoxins. There were also significant differences in isovalerate and $\mathrm{NH}_{3}-\mathrm{N}$ levels, and significant differences in the eight plasma metabolites among the three groups. These metabolites are mainly involved in amino acid metabolism pathways. Therefore, the results suggest that amino acid metabolism pathways may be affected by mycotoxins exposure. . 


\section{The biochemical and metabolic profiles of dairy cows 2 with mycotoxins-contaminated diets}

5 Qian Wang $\rfloor^{1,2,3}$, Yangdong Zhang $\ddagger^{1,2,3}$, Nan Zheng, ${ }^{1,2,3}$ Shenguo Zhao ${ }^{1,2,3}$, Songli Li ${ }^{1,2,3}$, Jiaqi Wang ${ }^{1,2,3}$

$7{ }^{1}$ State Key Laboratory of Animal Nutrition, Institute of Animal Science, Chinese Academy of Agricultural 8 Sciences, Beijing, People's Republic of China;

$9 \quad 2$ Key Laboratory of Quality \& Safety Control for Milk and Dairy Products of Ministry of Agriculture and Rural 10 Affairs, Institute of Animal Sciences, Chinese Academy of Agricultural Sciences, Beijing, People's Republic of 11 China;

$12{ }^{3}$ Laboratory of Quality and Safety Risk Assessment for Dairy Products of Ministry of Agriculture and Rural 13 Affairs, Institute of Animal Sciences, Chinese Academy of Agricultural Sciences, Beijing, People's Republic of 14 China.

$18 \$$ These authors contributed equally to this work.

Corresponding author:

21 Jiaqi Wang (J.Q. Wang)

22 Address: Institute of Animal Science, Chinese Academy of Agricultural Sciences, Haidian District, Beijing, PR 23 China.

24 Tel: +8610 62816069; fax: +861062897587.

25 E-mail: wangjiaqi@caas.cn (J.Q. Wang). 


\section{ABSTRACT}

27 Background: Previous studies on the effects of mycotoxins have solely focused on their biochemical 28 profiles or products in dairy ruminants. Changes in metabolism that occur after exposure to mycotoxins, as 29 well as biochemical changes, have not been explored.

30 Methods: We measured the biochemical and metabolic changes in dairy cows after exposure to mycotoxins

31 using biochemical analyses and nuclear magnetic resonance. Twenty-four dairy cows were randomly 32 assigned to three different treatment groups. Control cows received diets with $2 \mathrm{~kg}$ uncontaminated 33 cottonseed. Cows in the $50 \%$ replacement group received the same diet as the control group, but with $1 \mathrm{~kg}$ 34 of uncontaminated cottonseed and $1 \mathrm{~kg}$ of cottonseed contaminated with mycotoxins. Cows in the $100 \%$ 35 replacement group received the same diet as the control, but with $2 \mathrm{~kg}$ contaminated cottonseed.

36 Results: The results showed that serum $\gamma$-glutamyl transpeptidase and total antioxidant capacities were 37 significantly affected by cottonseed contaminated with mycotoxins. There were also significant differences 38 in isovalerate and $\mathrm{NH}_{3}-\mathrm{N}$ levels, and significant differences in the eight plasma metabolites among the three 39 groups. These metabolites are mainly involved in amino acid metabolism pathways. Therefore, the results 40 suggest that amino acid metabolism pathways may be affected by mycotoxins exposure. 


\section{INTRODUCTION}

49 Mycotoxins are toxic secondary metabolites produced mainly by pathogenic molds that infect plants or crops, 50 and by fungi in the genera Aspergillus, Fusarium, and Penicillium (Fink-Gremmels, 2008). Several hundred mycotoxins from animal feed have been identified and different studies have shown that most feed samples were infected with at least one mycotoxin (Rodrigues \& Naehrer, 2012). The main types of mycotoxins that are extremely harmful to animals and their products are aflatoxins, deoxynivalenol (DON), zearalenone (ZEA), T2 toxin, fumonisin, and ochratoxin A (Fink-Gremmels, 2008; Rodrigues \& Naehrer, 2012).

Because of the potential hazards of mycotoxins, the effect of mycotoxins on dairy animal health is a major concern (Fink-Gremmels, 2008). Dairy cows may be regularly exposed to a mixture of mycotoxins derived from different ingredients in their diets. However, previous studies focused on investigating basic blood biochemical parameters and animal performance suggest that dairy cows are more unresponsive to mycotoxins than monogastric livestock because mycotoxins are readily degraded by rumen microbes (Dänicke et al., 2010; Pier, 1992; Santos \& Fink-Gremmels, 2014). This was supported by the result that milk production tended not to decrease in lactating ewes fed diets contaminated with aflatoxin B1 (AFB1) (Battacone et al., 2009). Additional data has found that even calves are able to tolerate moderate feeding with different amounts of grains that are naturally contaminated with Fusarium toxins (Martin et al., 2010). Nevertheless, it is possible that dairy ruminants are more vulnerable to mycotoxins under high pressure of milk production (Jouany et al., 2005; Santos \& Fink-Gremmels, 2014). Previous studies have demonstrated that exposure to AFB1 or mixed mycotoxins can change the antioxidant states of dairy cows and goats (Huang et al., 2018; Xiong et al., 2015), and it is possible that these changes may be reflected at minor physical levels. Thus, the effects of mycotoxins on animal performance still require further investigation.

Some studies have examined the effects of mycotoxins from the perspectives of molecular biology and metabolomics. In particular, it has been shown that exposure to AFB1 can influence the Nrf2 signaling pathway via mitochondrial reactive oxygen species (ROS)-dependent signaling pathways, specifically by impairing mitochondria functions and activating the generation of ROS (Liu \& Wang, 2016). Mycotoxins can thus impair metabolic status, so it is necessary to investigate the dangers of mycotoxin contamination. Nuclear magnetic resonance (NMR) spectroscopy is a relatively simple method that can provide rich information about biochemical processes that are sensitive to the dynamic metabolic status of the organism (Maher \& Rochfort, 2014; Nicholson \& Wilson, 2003). Many metabolomics studies in different organisms have been conducted using NMR after exposure to mycotoxins (Cheng et al., 2017; Liu et al., 2013; Zhang et al., 2011). AFB1 exposure can significantly increase glucose and fatty acid levels, but according to NMR analyses, it can reduce the concentrations of lactate, ketone bodies, and amino acids in the serum (Cheng et al., 2017). Specific blood metabolites of dairy goats were induced by AFB1 exposure, indicating that endogenous metabolic alterations occur after exposure to mycotoxins. Therefore, changes in blood metabolic substrates of dairy ruminants can 
Gremmels, 2008; Huang et al., 2018).

Despite several related studies, little research has been conducted on the potential metabolic signatures of dairy cows when exposed to mycotoxins. In the present study, we assessed biochemical parameters that reflect basic physiological conditions and changes in biomarkers based on plasma metabolomics using NMR investigation.

\section{MATERIALS AND METHODS}

\section{Preparation of diets contaminated with mycotoxins}

Mycotoxins were cultivated and enriched on cottonseed contaminated with toxigenic fungi. We added water at a ratio of $30 \%$ relative to the weight of the uncontaminated cottonseed, and uniformly mixed the water and cottonseed. The wet cottonseed was then covered and placed in a relatively closed environment in order to facilitate the growth of fungi and accumulation of mycotoxins in the mixture. We measured the concentration of mycotoxins every 3 days (the cultivation period was set at 15 days, based on pilot experiments). When the AFB1 concentration in the cottonseed reached a suitable level, we dried the cottonseed out of the sunlight to stop the accumulation of mycotoxins.

\section{Determination of mycotoxins in contaminated cottonseed}

An AFB1 concentration of $20 \mu \mathrm{g} / \mathrm{kg}$ in the diet (dry matter) was the target concentration based on the limit specified by the European Union (EU) (European Commission, 2002). Additionally, the concentrations of two other mycotoxins, ZEA and DON, were also tested.

The concentrations of AFB1, ZEA, and DON were determined using the ROSA FAST Quantitative Test (Charm Sciences Inc, Lawrence, MA, USA). Five g of contaminated ground cottonseed was mixed with $5 \mathrm{~mL}$ of methanol or water, and then shaken for $3 \mathrm{~min}$. Next, $100 \mu \mathrm{L}$ of the supernatant was removed and mixed with $1 \mathrm{~mL}$ of dilution buffer. Finally, $100 \mu \mathrm{L}$ of the mixture was removed with a micropipette and spotted onto the test strip placed in an incubator for $5 \mathrm{~min}$. The results were visually interpreted by two trained technicians using the ROSA Reader (ROSA Pearl Reader, Charm Sciences Inc., Lawrence, MA, USA). The results showed that 1 $\mathrm{kg}$ of contaminated cottonseed contained $20.08 \mu \mathrm{g}$ AFB1 and $80.13 \mu \mathrm{g}$ ZEA, but DON was not detected.

\section{Animals, diets, and experimental design}

The experiment was conducted at Ningxia Helan Sinofarm Dairy Farm (Ningxia, China) from December 17, 2015 to December 31, 2015 with an experimental period of 14 days. In total, 24 multiparous Holstein cows in late lactation (lactation length $=283 \pm 22$ days, milk yield $=21.1 \pm 2.6 \mathrm{~kg} / \mathrm{day}$, parity $=2.5-3.5$ times) were used in this study. The cows were raised in an open-sided, free stall barn with a sand bed, and were equipped with neck clips to allow a measured feed intake. Each of the three treatments had eight individuals randomly assigned to them. Cows in the control group received the uncontaminated diet (which included $2 \mathrm{~kg}$ of uncontaminated cottonseed). Cows in the 50\% replacement group received the same diet as the control group, but the cottonseed component had $1 \mathrm{~kg}$ of uncontaminated cottonseed and $1 \mathrm{~kg}$ of cottonseed contaminated with mycotoxins. Cows in the $100 \%$ replacement group received the same diet as the control group, but the cottonseed 
118

119

component had $2 \mathrm{~kg}$ of cottonseed contaminated with mycotoxins (Table 1). Feedings occurred at 8:30, 16:30, and 00:30.

All of the experimental procedures were approved by the Animal Care and Use Committee of the Institute of Animal Science, Chinese Academy of Agricultural Sciences (Protocol: IAS15020). The diets were formulated to meet and exceed the nutrient requirements for lactating Holstein cows (NRC, 2001). The ingredients, nutrients, and energy contents of the basal diets are listed in Table 1.

\section{Sample collection and test methods}

\section{Diet samples}

Diet samples were weighed, dried at $65^{\circ} \mathrm{C}$ for $72 \mathrm{~h}$, and stored at $-20^{\circ} \mathrm{C}$ for subsequent analyses. The nutrient, energy, and mineral ion indices were analyzed, including crude protein, fat, $\mathrm{Ca}, \mathrm{P}$, ash, non-fiber carbohydrate, and neutral detergent fiber (Table 1).

\section{Blood parameters}

Blood samples were collected from the jugular vein using vacutainer tubes (with and without anticoagulant) after milking on day 7 . The samples were allowed to settle for about $1 \mathrm{~h}$ before centrifugation at $3000 \times g$ and $4^{\circ} \mathrm{C}$ for $20 \mathrm{~min}$ to obtain serum, which was then frozen at $-70^{\circ} \mathrm{C}$ for subsequent analyses. The serum samples were analyzed to determine routine biochemical parameters using an Auto-Analyzer 7020 (Hitachi HighTechnologies Corp., Tokyo, Japan) with colorimetric commercial kits (DiaSys Diagnostics Systems GmbH, Holzheim, Germany). Tested parameters included: alanine aminotransferase (ALT), aspartate aminotransferase (AST), $\gamma$-glutamyl transpeptidase (GGT), alkaline phosphatase (ALP), total protein, albumin, globulin, albumin/globulin ratio, urea, creatinine, uric acid, total bilirubin, direct bilirubin, indirect bilirubin, triglycerides, and total cholesterol. Another set of serum samples for determining immune and antioxidant indices was sent to Beijing CIC Clinical Laboratory (Beijing, China), where the concentrations of immunoglobulin M (IgM), IgA, and $\mathrm{IgG}$ were determined using bovine immunoglobulin ELISA kits (Shanghai Meilian BioTech Company, Shanghai, China). The methods used to determine the total antioxidant capacity (T-AOC), superoxide dismutase (SOD), glutathione peroxidase (GSH-Px), and malondialdehyde (MDA) levels were described in previous studies (Cheng et al., 2017; Xiong et al., 2015).

\section{Concentrations of volatile fatty acids (VFAs) and $\mathrm{NH}_{3}-\mathrm{N}$ in rumen fluid}

Rumen fluid was collected using an oral stomach tube about $1 \mathrm{hr}$ after the morning feeding on day 7 , as described in a previous study (Shen et al., 2012). The first 50-100 $\mathrm{ml}$ of flowing liquid was discarded to avoid contamination with saliva, and the oral stomach tube was washed twice using fresh water before the next sampling. The concentrations of rumen VFAs were determined using a gas chromatography system equipped with flame ionization (GC 6890N, Agilent, Wilmington, DE). The rumen liquid was deproteinized with $2.0 \mathrm{~mL}$ of 25\% metaphosphoric acid and frozen before each VFA analysis. Helium was used as the carrier gas, and a mixture of six species of VFAs (Supelco Inc., Bellefonte, PA, USA) was used as the identification standard. The initial and final temperatures in the oven were $55^{\circ} \mathrm{C}$ and $195^{\circ} \mathrm{C}$, respectively, and the detector and injector were set to $250^{\circ} \mathrm{C}$. The samples of deproteinized ruminal fluid were neutralized with potassium hydroxide solution 
154

155

156

157

158

159

160

161

162

163

164

165

166

167

168

169

170

171

172

173

174

175

176

177

178

179

180

181

182

183

184

185

186

187

188

189

and then centrifuged at $1200 \times g$ for $10 \mathrm{~min}$. Ruminal $\mathrm{NH}_{3}-\mathrm{N}$ was analyzed with a UV-2000 ultraviolet visible spectrophotometer (Unico Instrument Co. Ltd, Shanghai, China).

\section{Metabolomic analysis of plasma by $1 \mathrm{H}$ NMR}

Deuterium oxide $\left(\mathrm{D}_{2} \mathrm{O}\right)$ and deuterated chloroform were purchased from Cambridge Isotope Laboratories, Inc. (Tewksbury, MA, USA). In addition, 3-(trimethylsilyl) propionic-2,2,3,3,d4 propionic acid sodium salt was purchased from Merck Inc. (Kirkland, QC, Canada). HPLC-grade methanol, methyl tert-butyl ether, water, formic acid, and ammonium formate were purchased from Merck (Darmstadt, Germany).

Twenty-four frozen plasma samples were thawed at room temperature and $200 \mu$ of each sample was mixed with $400 \mu \mathrm{l}$ of buffer ( $45 \mathrm{mM} \mathrm{NaH} \mathrm{PO}_{4} / \mathrm{K}_{2} \mathrm{HPO}_{4} ; 0.9 \% \mathrm{NaCl} ; \mathrm{pH}: 7.4 ; 50 \% \mathrm{D}_{2} \mathrm{O}$ ). After shaking and mixing, the sample was centrifuged at $4^{\circ} \mathrm{C}$ and $16,099 \times g$ for $10 \mathrm{~min}$. The supernatant was placed in a $5-\mathrm{mm}$ NMR tube for examination. A Bruker AVIII $600 \mathrm{MHz}$ NMR (proton resonance frequency $=600.13 \mathrm{MHz}$, ultra-low temperature probe; Bruker BioSpin GmbH, Rheinstetten, Germany) system was used for 1H NMR analysis of the blood samples.

In order to attenuate the NMR signals to avoid the influence of macro-molecules, a water-pre-saturated Carr-Purcell-Meiboom-Gill (CPMG) pulse sequence was employed (recycle delay- $90^{\circ}-\left(\tau-180^{\circ}-\tau\right)_{n^{-}}$ acquisition). A one-dimensional CPMG pulse sequence with pre-saturated pressurized water was used to detect the small molecule metabolites in each sample. The experimental parameters were as follows: spectral width, 12,000 Hz; waiting time, $2 \mathrm{~s}$; mixing time, $100 \mathrm{~ms}$; and sampling number, 32K. NMR spectra were manually phased, baseline corrected, and referenced to TSP $(\mathrm{CH} 3,80.00)$ using Bruker Topspin 3.0 software (Bruker $\mathrm{GmbH}$, Karlsruhe, Germany). NMR spectra were visually inspected using Amix 3.9.13 (Bruker, Biospin, Italy). Finally, the NMR spectra were integrated over the 9.0-0.5 ppm range using an interval of $0.002 \mathrm{ppm}$ and the water peak ( $\delta$ 5.20-4.20) was removed.

\section{Data analysis}

Blood biochemical parameters, antioxidant and immune indices, rumen fluid VFA levels, and $\mathrm{NH}_{3}-\mathrm{N}$ data were analyzed using analysis of variance in SPSS Statistics, and post-hoc tests were conducted (IBM SPSS Statistics v19.0, SPSS Inc., Chicago, IL, USA). The statistical models included treatments as the fixed effects and cows within treatment as the random effect. The data for food intake and milk yield before the first day of the treatment period were used as a covariate in the statistical analysis. Tukey's multiple comparisons adjustment was used to determine significant differences between least squares means. Statistically significant differences were accepted at $P<0.05$.

The 1H NMR spectra were subjected to Fourier transformation, phase adjustment, baseline correction, and calibration using MestReNova V7.0 software (Mestrelab Research SL, Santiago de Compostela, Spain). To improve the signal-to-noise ratio, all of the spectra were multiplied by an exponential function of $1 \mathrm{~Hz}$ before Fourier transformation. The $1 \mathrm{H}$ NMR spectra were referenced to an internal lactic acid $\mathrm{CH}_{3}$ resonance at 1.33 $\mu \mathrm{g} / \mathrm{kg}$. The $1 \mathrm{H}$ NMR spectra were segmented into consecutive non-overlapping regions comprising $0.002 \mu \mathrm{g} / \mathrm{kg}$ chemical shift "bins" between 0.5 and $9.0 \mu \mathrm{g} / \mathrm{kg}$. The residual water peak at 4.18-6.70 $\mu \mathrm{g} / \mathrm{kg}$ was removed from 
190

191

192

193

the data. The normalized data were analyzed by multivariate analysis using SIMCA-P+ software (V11.0 Umetrics AB, Umea, Sweden). First, the $1 \mathrm{H}$ NMR spectra were analyzed using principal component analysis (PCA) based on mean center scaling to reflect the overall differences. Next, the spectra were analyzed by supervised methods of partial least-squares discriminant analysis (PLS-DA) and orthogonal partial least-squares discriminant analysis (OPLS-DA) (Lundstedt et al., 2007). The quality of each model was determined based on the goodness of fit parameter (R2) and a goodness of prediction parameter (Q2) (Eriksson et al., 2008). The statistical significances of differences in the metabolite concentrations and appropriate correlation coefficients were determined by OPLS-DA.

\section{RESULTS}

\section{Blood biochemical, antioxidant, and immune parameters}

There were no significant differences in most of the serum parameters (Table 2). However, there was a significant difference in GGT between the control group and the 50\% replacement group $(P<0.05)$, although there was no significant difference in GGT between the control group and the $100 \%$ replacement group. In addition, the difference in T-AOC between the control group and the $100 \%$ replacement group reached a very significant level, but there was no significant difference between T-AOC in the control group and the 50\% replacement group.

\section{Rumen function}

The ruminal concentrations of VFAs and $\mathrm{NH}_{3}-\mathrm{N}$ were used as indicators of rumen fermentation and the effects of dietary treatments. We found that mycotoxins significantly increased $(P<0.05)$ the rumen $\mathrm{NH}_{3}-\mathrm{N}$ concentration in the $100 \%$ replacement group but not in the $50 \%$ replacement group (Figure 1a). In addition, the contaminated cottonseed did not affect the total amount of rumen VFAs (Figure 1b). Interestingly, the different levels of added contaminated cottonseed did not affect the concentrations of acetate, propionate, butyrate, and valerate, but the contaminated cottonseed had significant effects on isovalerate $(P<0.05)$ (Table 3). The isovalerate concentrations in the control group differed from those in the $50 \%$ replacement group $(P<$ 0.05 ), but there were no significant differences between the control group and the $100 \%$ replacement group.

\section{Metabolomic profiling of plasma based on NMR analysis}

Representative 1H NMR spectra $(\delta 9.0-0.5)$ of the plasma samples obtained from the control group, $50 \%$ replacement group, and 100\% replacement group are shown in Figure 2. These metabolites were identified and compared based on data obtained from a previous study (Nicholson \& Wilson, 2003) and the ChenomX spectral database (Edmonton, AB, Canada). The data were subsequently analyzed using multivariate statistics, i.e., PCA, PLS-DA, and OPLS-DA.

To obtain an overview of the data, PCA was performed to identify the two principal components (PC1 and PC2), where the cumulative variance contribution rate of the $1 \mathrm{H}$ NMR spectra was $90.9 \%$ (PC1 $=81.5 \%$ and PC2 $=9.4 \%$ ) (Figure 3A). However, there was some overlap and one or two discrete values. Figures 3B, 3C, and 3D show that the control and the 50\% replacement group, the control and the $100 \%$ replacement group, and 
225

226

227

228

229

230

231

232

233

234

235

236

237

238

239

240

241

242

243

244

245

246

247

248

249

250

251

252

253

254

255

256

257

258

259

the 50\% replacement and 100\% replacement group, respectively, were not well separated from each other, so it was necessary to use supervised methods for further analysis. OPLS-DA increased the number of principal components until the variance explained by the model (R2) or the predictive variance of the model (Q2) reached $2 \%$. The validity of the model was established by conducting cross and permutation tests (200 times). After this procedure, OPLS-DA score plots (left panel; A, D, and $\mathbf{G}$ ) derived from 1H NMR spectra for plasma and the corresponding coefficient loading plots (right panel; B, C, E, F, H, and $\mathbf{I}$, in which, B, E and $\mathbf{H}$ are images magnified 20 times) were shown in Figure4, the control and 50\% replacement groups were discriminated with $\mathrm{R} 2 \mathrm{X}=32.5 \%$ and Q2 $=0.4$ (Figure 4A), the control and 100\% replacement groups with R2X $=29.3 \%$ and Q2 $=0.374$ (Figure 4D), and the $50 \%$ and $100 \%$ replacement groups with $\mathrm{R} 2 \mathrm{X}=26.5 \%$ and $\mathrm{Q} 2=0.316$ (Figure 4G).

The plasma spectra mainly contained signals from glycoproteins, glucose, amino acids, creatinine, and citrate metabolites. The plasma concentrations of the eight metabolites differed significantly among the three groups according to the results obtained by $1 \mathrm{H}$ NMR analysis (Table 4), particularly amino acids comprising alanine, lysine, glutamine, and glycine, the carboxylic acids creatinine and citrate, glucose, and O-acetylglycoprotein. Using the metabolomics view map derived from pathway topology analysis (MetaboAnalyst 3.0), we found the enrichment analysis and path impact values of different pathways. The pathways ranked in the top three were aminoacyl-tRNA biosynthesis, nitrogen metabolism and alanine, and aspartate and glutamate metabolism (Figure 5).

\section{DISCUSSION}

\section{Biochemical parameters in blood}

Many components of blood can reflect physiological functions as well as immune and antioxidant activities in the body. For example, GGT, AST, ALT, and ALP are used as liver function indicators (Edrington et al., 1994; Xiong et al., 2015). We found no significant differences in most of the serum parameters in the control and two treatments. However, two variables were affected by the intake of mycotoxins. The blood concentration of GGT is considered an indicator of liver function in ruminants (Osorio et al., 2014; Xiong et al., 2015). Thus, in the present study, the significant difference in GGT between the control group and 50\% replacement group suggests that liver function was affected by contaminated cottonseed, although it is unclear why the levels did not change significantly in the $100 \%$ replacement group. Mycotoxins can influence liver function, but its effects fluctuate according to toxin dose and duration. A daily intake of 3-128 $\mu \mathrm{g}$ /day of pure AFB1 for one week did not alter the activities of several enzymes related to liver function in dairy sheep (Battacone et al., 2005), but the blood activity level of ALT increased significantly in dairy ewes after the intake of a high dose of AFB1 (128 $\mu \mathrm{g} /$ day) for two weeks (Battacone, 2003). In lambs fed $2.5 \mathrm{mg} / \mathrm{kg}$ AFB1 for 35-67 days, the serum GGT and AST levels increased significantly (Edrington et al., 1994). However, in a different study, AFB1 did not affect the plasma concentrations of AST, ALT, GGT, nor ALP in dairy cows (Xiong et al., 2015).

A previous study showed a slightly stronger reaction to $20 \mu \mathrm{g} / \mathrm{kg}$ AFB1 than $40 \mu \mathrm{g} / \mathrm{kg}$ AFB1, which was 
260

261

262

263

264

265

266

267

268

269

270

271

272

273

274

275

276

277

278

279

280

281

282

283

284

285

286

287

288

289

290

291

292

293

294

295

reflected by the MDA levels (Xiong et al., 2015). Aspartate aminotransferase (AST), one of the most important transaminases, is an indicator of liver function in clinical medicine used to judge whether the liver is damaged. Data has shown that the group fed a meal without mycotoxins, the group fed AFB1, and the group fed AFB1 mixed with ZEA had similar serum AST levels, but the group fed AFB1 mixed with OTA showed significantly higher levels than that of the three groups. Moreover, the group fed AFB1 mixed with OTA and ZEA had significantly higher levels than that of the abovementioned four groups (Huang et al., 2018). These results may hint that mycotoxin type and amount are key factors that can affect animal health performances.

The serum concentrations of IgM, IgA, and IgG in the present study did not change significantly, suggesting that the contaminated cottonseed did not affect the immune functions of the dairy cows. Similar results were found in other studies (Korosteleva et al., 2007; Xiong et al., 2015), but it is possible that the response to mycotoxins may be reflected in other immune factors. Additional parameters were not tested in the current study, and immune function measures are required for further comprehensive analysis.

Previous studies have shown that mycotoxins can influence animal oxidant stress levels. SOD and MDA are used as indices of the degree of lipid peroxidation, and the SOD/MDA ratio can reflect free radical-induced lipid peroxidation and the scavenging rate (Surai, 2002; Xiong et al., 2015). For example, mycotoxins increase the MDA concentration, but decrease the SOD concentration in dairy goats (Huang et al., 2018). In the present study, we found that the $100 \%$ replacement group had a lower concentration of serum T-AOC compared with the other two groups. Since T-AOC is an indicator of overall biochemical antioxidant capacity, it reflects the systemic ability of antioxidative enzymes and non-antioxidative enzymes to compensate for external stress and the capacity to clear free radicals (Surai, 2002). Therefore, lower T-AOC levels may indicate that contaminated cottonseed affected the overall antioxidant capacity of dairy cows. A previous study showed that the reaction to $20 \mu \mathrm{g} / \mathrm{kg}$ AFB1 was slightly stronger than the reaction to $40 \mu \mathrm{g} / \mathrm{kg}$ AFB1, which was reflected by the MDA level and SOD/MDA ratio (Xiong et al., 2015). It should be noted that subtle changes may affect overall antioxidant capacity in response to toxins (but not at a significant level), which may be sporadically detected in terms of other oxidative indicators, such as SOD, MDA, and GSH-Px.

\section{Rumen function}

Feedstuffs (e.g., plant constituents, fiber, and cellulose) are fermented in the rumen of dairy cows with the aid of rumen microbes, bacteria, protozoa, and fungi. Evidence suggests that rumen microbiota can protect animals by binding, deactivating, and degrading toxic molecules (Fink-Gremmels, 2008).

Rumen microorganisms convert carbohydrates into VFAs, and these organic acids are absorbed through the gastrointestinal tract into the circulatory system to reach different tissues. VFAs are consequently an essential energy resource for ruminants. The rumen concentration of VFAs has been used as an indicator of rumen fermentation and the effects of dietary treatments (Hall et al., 2015; Xiong et al., 2015). In the present study, the different levels of contaminated cottonseed affected isovalerate but did not affect the concentrations of total VFAs, acetate, propionate, butyrate, isobutyrate, and valerate (Figure 1 and Table 3). A recent study suggested that the concentration of total VFAs in rumen is not an appropriate indicator of ruminal fermentation or microbial 
296

297

298

299

300

301

302

303

304

305

306

307

308

309

310

311

312

313

314

315

316

317

318

319

320

321

322

323

324

325

326

327

328

329

330

331

product formation because of the high daily variation in the amount of rumen fluid (Hall et al., 2015), and this finding was supported by another study (Xiong et al., 2015). Thus, it may be more useful to investigate the levels of specific types of VFAs. Isovalerate, isobutyric acid, and 2-methyl butyrate belong to the family of isoacids. Previous studies have indicated that isoacids promote the growth of anaerobic bacteria in the rumen fluid and degrade fiber in the rumen (Liu et al., 2014). In vitro analyses of rumen fermentation have shown that isoacids can promote the growth of micro-organisms and the degradation of fiber after adding a mixture of isobutyrate, 2-methyl butyrate, and isovalerate (Gunter et al., 1990). Thus, the significant differences in isovalerate levels in the present study may indicate that rumen fermentation is influenced by contaminated cottonseed. However, similar experiments were inconclusive in many previous animal studies. A similar study found that mixed mycotoxins significantly increased $\mathrm{NH}_{3}-\mathrm{N}$ and total VFA concentrations (Kiyothong et al., 2012). Another study found that the acetate:propionate ratio in the rumen of dairy cows was influenced by supplementation with 20 $\mu \mathrm{g} / \mathrm{kg}$ AFB1 (Xiong et al., 2015). Other studies found no evidence that feeding with isoacids improved digestibility in the rumen (Gunter et al., 1990), with one study in particular showing that supplementation with isoacids does not change digestibility of dry material, fiber, and crude protein in steers (McCollum et al., 1987).

In the present study, the significant difference in rumen isovalerate between the control and $50 \%$ replacement groups may suggest that rumen fermentation was affected by contaminated cottonseed. It is unclear why the levels did not change significantly in the $100 \%$ replacement group. The experimental data of isovalerate addition showed that the low, middle and high doses (100, 200, and $300 \mathrm{mg}$ per DMI) were not consistent with our expectations. The rumen isobutyrate content in the middle dose was the highest. Rumen isobutyrate levels in the low dose group were the same as in the control group (Liu et al., 2009). Further research is needed to clarify the relationships between mycotoxins, diet, and the concentrations of specific VFA in the rumen.

A suitable concentration of $\mathrm{NH}_{3}-\mathrm{N}$ is an important mediator in rumen nitrogen metabolism. We found that mycotoxins significantly increased the $\mathrm{NH}_{3}-\mathrm{N}$ concentration in the rumen in the $100 \%$ replacement group (Figure 1). The most suitable ruminal $\mathrm{NH}_{3}-\mathrm{N}$ concentration for growth ranges between 5.0 and $28.0 \mathrm{mg} / 100 \mathrm{~mL}$ (Wanapat \& Pimpa, 1999). However, $\mathrm{NH}_{3}-\mathrm{N}$ concentration in the $100 \%$ replacement group went beyond the upper limit of this range, suggesting that the microbial protein decomposition capacity could be imbalanced (Wanapat \& Pimpa, 1999). The contaminated cottonseed may have affected the microbial degradation of proteins and the synthesis of ammonia, for two possible reasons. First, isovalerate could have promoted the utilization of microbial nitrogen to produce $\mathrm{NH}_{3}-\mathrm{N}$, thereby leading to increased microbial protein synthesis (Allison, 1969). Second, the rumen $\mathrm{NH}_{3}-\mathrm{N}$ concentration was reduced due to the decreased rate of protein degradation. Our results showed that the decrease in isovalerate may have led to the reduced utilization of $\mathrm{NH}_{3}-\mathrm{N}$ by rumen microbes, or some other mechanism related to in vivo nitrogen retention may have been partially blocked in the rumen (Felix et al., 1980).

\section{Analysis of plasma metabolites and metabolic pathways}

Feedstuffs can have important effects on the performances of dairy cows, and metabolomics can help us accurately understand the causes of metabolic changes and their subsequent effects (Cheng et al., 2017; 
332

333

334

335

336

337

338

339

340

341

342

343

344

345

346

347

348

349

350

351

352

353

354

355

356

357

358

359

360

361

362

363

364

365

366

367

Sundekilde et al., 2013). In the present study, eight plasma metabolites differed significantly among the three groups. These metabolites were mainly involved in the metabolic pathways related to aminoacyl-tRNA biosynthesis, nitrogen metabolism, and alanine, aspartate, and glutamate metabolism (Table 4 and Figure 5). Interestingly, four amino acids included in the eight metabolites differed significantly in the present study, indicating that amino acid metabolism was affected by the mycotoxins. Previous studies have shown that mycotoxins can influence energy expenditure and protein metabolism (Sun et al., 2014; Sundekilde et al., 2013). Generally, the balance of amino acids is regulated by the relative rates of synthesis and degradation. Studies suggest that acylated amino acids to $t$ RNA are the immediate precursors to protein synthesis and that each amino acid is catalyzed by a specific synthase that combines with the corresponding $t$ RNA (Davis et al., 1999; Martin et al., 1977). However, the aminoacyl-tRNA concentration is very low and extremely unstable within cells and tissues, and previous studies have shown that $t$ RNA plays an important regulatory role in the gene expression process within the dairy cow's mammary gland (Bauman et al., 2006; Mackle et al., 2000; Wang et al., 2014). When an organism encounters external stress, the unloaded $t$ RNA can act as an effector for the overall gene expression levels in the cell, thereby allowing the organism to cope with an adverse environment. $t$ RNA can be used for this purpose in yeast and some mammalian cells. The nucleus monitoring system can continuously monitor the integrity of $t$ RNA, and in the absence of nutrition, the retrograde transport of $t$ RNA into the nucleus can effectively reduce the level of protein synthesis (Davis et al., 1999; Martin et al., 1977). Previous studies have suggested that investigations of the effects of mycotoxins on animal metabolism should focus specifically on amino acid metabolism.

Nitrogen metabolism (nitrogen balance) mediates the relationship between nitrogen intake and excretion. Previous studies have indicated that feed constituents can influence nitrogen metabolism in dairy cows (Cantalapiedra-Hijar et al., 2014; Otto et al., 2003). Amino acids are important nutrients in cow milk (Sundekilde et al., 2013) and a major aspect of ruminant protein nutrition research involves studying the digestion and absorption of feed proteins (Cantalapiedra-Hijar et al., 2014; Castillo et al., 2001). Nitrogen balance can directly affect health status and pasture waste management (Arriaga et al., 2009). In the present study, the nitrogen metabolism pathway was significantly affected, probably due to the effects of mycotoxins on the synthesis and degradation of amino acids. The involved mechanism may influence glucogenic nutrients and the utilization of amino acids. The amino acids that remain in the body after utilization by the liver and intestines are transferred to the peripheral organs and tissues or excreted as waste. Thus, the visceral organs may play a regulatory role in nitrogen metabolism in order to limit the systemic availability of absorbed amino acids to the peripheral tissues (Cantalapiedra-Hijar et al., 2014; Larsen et al., 2015).

Our results also illustrate that mycotoxins affect glucose metabolites in the blood, thereby influencing glucose metabolism. Previous studies have shown that mycotoxin-contaminated feed can affect glucose metabolism, specifically by decreasing the activities of intestinal glucose transporters (Bertrand \& Applegate, 2013; Liu et al., 2013; Zhang et al., 2011). Glucogenic amino acids are involved in the regulation of glucose metabolism (Xu et al., 2008). Branched-chain amino acids may inhibit glycogenolysis in the liver and muscles, 
368

369

370

371

372

373

374

375

376

377

378

379

380

381

382

383

384

385

386

387

388

389

390

391

392

393

and can enhance the alanine-glucose and lactic acid-glucose cycles (Hayirli, 2006). Alanine, aspartate, and glutamate are glucogenic amino acids. Glutamate is a functional amino acid with important physiological regulatory functions (Duan et al., 2013; Zhang et al., 2013). We found that feed contaminated with mycotoxins had significantly affected alanine, aspartate, and glutamine metabolism pathways, indicating that body gluconeogenesis is also influenced by the mycotoxins.

In the present study, we found significant differences in the O-acetyl-glycoprotein, citrate, and creatinine concentrations among the three treatment groups. A previous study similarly showed that exposure to ZEA significantly elevated the plasma levels of glucose and O-acetyl glycoprotein (Liu et al., 2013). NMR has been used to identify the milk metabolites obtained from two dairy cow breeds (Danish and Jersey Holstein), and they found choline, creatinine, and citrate, which are also potential biomarkers (O'Sullivan et al., 2013; Pinotti et al., 2002). Our findings suggest that O-acetyl-glycoprotein, citrate, and creatinine may be used as potential biomarkers of altered metabolism.

\section{CONCLUSION}

Diets containing cottonseed contaminated with mycotoxins significantly influenced the blood GGT content and T-AOC of dairy cows. Significant differences in isovalerate and $\mathrm{NH}_{3}-\mathrm{N}$ concentrations were also found between the control and treatment groups, indicating that the contaminated cottonseed may have influenced ruminal function. Moreover, among the three treatment groups, there were significant differences in the eight plasma metabolites mainly involved in the aminoacyl-tRNA biosynthesis, nitrogen metabolism, and alanine, aspartate, and glutamate metabolism pathways. These differences suggest that amino acid metabolism pathways may be important targets when investigating the effects of mycotoxin exposure in future research.

\section{Acknowledgments}

We sincerely thank Dr. Cheng, his graduate students, and the farm staff for their help in this experiment. We also sincerely thank the anonymous reviewers for their revision suggestions.

Peer) reviewing PDF | (2018:12:33919:2:1:NEW 12 Feb 2020) 
394

395

396

397

398

399

400

401

402

403

404

405

406

407

408

409

410

411

412

413

414

415

416

417

418

419

420

421

422

423

Allison M. 1969. Biosynthesis of amono acids by ruminal microorganisms. Journal of Animal Science 29:797-807

Arriaga H, Pinto M, Calsamiglia S, Merino P. 2009. Nutritional and management strategies on nitrogen and phosphorus use efficiency of lactating dairy cattle on commercial farms: An environmental perspective. Journal of Dairy Science 92:204-215

Battacone G. 2003. Excretion of Aflatoxin M1 in Milk of Dairy Ewes Treated with Different Doses of Aflatoxin B1. Journal of Dairy Science 86:2667-2675

Battacone G, Nudda A, Palomba M, Mazzette A, Pulina G. 2009. The transfer of aflatoxin M1 in milk of ewes fed diet naturally contaminated by aflatoxins and effect of inclusion of dried yeast culture in the diet. Journal of Dairy Science 92:4997-5004

Battacone G, Nudda A, Palomba M, Pascale M, Nicolussi P, Pulina G. 2005. Transfer of aflatoxin B1 from feed to milk and from milk to curd and whey in dairy sheep fed artificially contaminated concentrates. Journal of Dairy Science 88:3063-3069

Bauman DE, Mather IH, Wall RJ, Lock AL. 2006. Major advances associated with the biosynthesis of milk. Journal of Dairy Science 89:1235-1243

Bertrand G, Applegate TJ. 2013. Modulation of intestinal functions following mycotoxin ingestion: meta-analysis of published experiments in animals. Toxins 5:396-430

Cantalapiedra-Hijar G, Lemosquet S, Rodriguez-Lopez JM, Messad F, Ortigues-Marty I. 2014. Diets rich in starch increase the posthepatic availability of amino acids in dairy cows fed diets at low and normal protein levels. Journal of Dairy Science 97:5151-5166

Castillo AR, Kebreab E, Beever DE, Barbi JH, Sutton JD, Kirby HC, France J. 2001. The effect of protein supplementation on nitrogen utilization in lactating dairy cows fed grass silage diets. Journal of Animal Science 79:247-253

Cheng J, Huang S, Fan C, Zheng N, Zhang Y, Li S, Wang J. 2017. Metabolomic analysis of alterations in lipid oxidation, carbohydrate and amino acid metabolism in dairy goats caused by exposure to Aflotoxin B1. Journal of Dairy Research 84:401-406

Dänicke S, Matthäus K, Lebzien P, Valenta H, Stemme K, Ueberschär KH, Razzazi-Fazeli E, Böhm J, Flachowsky G. 2010. Effects of Fusarium toxin-contaminated wheat grain on nutrient turnover, microbial protein synthesis and metabolism of deoxynivalenol and zearalenone in the rumen of dairy cows. Journal of Animal Physiology \& Animal Nutrition 89:303-315 
424

425

426

427

428

429

430

431

432

433

434

435

436

437

438

439

440

Davis TA, Fiorotto ML, Nguyen HV, Burrin DG. 1999. Aminoacyl-tRNA and tissue free amino acid pools are equilibrated after a flooding dose of phenylalanine. American Journal of Physiology 277:103-109

Duan J, Yin J, Wu M, Liao P, Deng D, Liu G, Wen Q, Wang Y, Qiu W, Liu Y. 2013. Dietary glutamate supplementation ameliorates mycotoxin-induced abnormalities in the intestinal structure and expression of amino acid transporters in young pigs. Plos One 9:e112357

Edrington TS, Harvey RB, Kubena LF. 1994. Effect of aflatoxin in growing lambs fed ruminally degradable or escape protein sources. Journal of Animal Science 72:1274-1281

Eriksson L, Johansson E, Kettanehwold N, Trygg J, Wikström C, Wold S. 2008. Multi- and Megavariate Data Analysis : Part II: Advanced Applications and Method Extensions. Umetrics Inc:362

Felix A, Cook RM, Huber JT. 1980. Isoacids and Urea as a Protein Supplement for Lactating Cows Fed Corn Silage. Journal of Dairy Science 63:1098-1103

Fink-Gremmels J. 2008. Mycotoxins in cattle feeds and carry-over to dairy milk: A review. Food Additives \& Contaminants 25:172-180

Gunter SA, Krysl LJ, Judkins MB, Broesder JT, Barton RK. 1990. Influence of branched-chain fatty acid supplementation on voluntary intake, site and extent of digestion, ruminal fermentation, digesta kinetics and microbial protein synthesis in beef heifers consuming grass hay. Journal of Animal Science 68:2885-2892

Hall MB, Nennich TD, Doane PH, Brink GE. 2015. Total volatile fatty acid concentrations are unreliable estimators of treatment effects on ruminal fermentation in vivo. Journal of Dairy Science 98:3988-3999

Hayirli A. 2006. The Role of Exogenous Insulin in the Complex of Hepatic Lipidosis and Ketosis Associated with Insulin Resistance Phenomenon in Postpartum Dairy Cattle. Veterinary Research Communications 30:749774

Huang S, Zheng N, Fan C, Cheng M, Wang S, Jabar A, Wang J, Cheng J. 2018. Effects of Aflatoxin B1 combined with Ochratoxin A and/or Zearalenone on Metabolism, Immune Function, and Antioxidant Status in Lactating Dairy Goats. Asian-Australasian Journal of Animal Sciences 31:505-513

Jouany JP, Diaz DE, Diaz DE. 2005. Effects of mycotoxins in ruminants. In: Diaz DE, editor. The mycotoxin blue book. Nottingham (UK): Nottingham University Press. pp 295-321

Kiyothong K, Rowlinson P, Wanapat M, Khampa S. 2012. Effect of mycotoxin deactivator product supplementation on dairy cows. Animal Production Science 52:832-841

Korosteleva SN, Smith TK, Boermans HJ. 2007. Effects of feedborne Fusarium mycotoxins on the performance, metabolism, and immunity of dairy cows. Journal of Dairy Science 90:3867-3873

Peer) reviewing PDF | (2018:12:33919:2:1:NEW 12 Feb 2020) 
454

455

456

457

458

459

460

461

462

463

464

465

466

467

468

469

470

471

472

473

474

475

476

477

Martin LM, Wood KM, McEwen PL, Smith TK, Mandell IB, Yannikouris A, Swanson KC. 2010. Effects of feeding corn naturally contaminated with Fusarium mycotoxins and/or a modified yeast cell wall extract on the performance, immunity and carcass characteristics of grain-fed veal calves. Animal Feed Science \& Technology 159:27-34

Larsen M, Galindo C, Ouellet DR, Maxin G, Kristensen NB, Lapierre H. 2015. Abomasal amino acid infusion in postpartum dairy cows: Effect on whole-body, splanchnic, and mammary amino acid metabolism. Journal of Dairy Science 98:7944-7961

Liu G, Tao Y, Jing W, Huang Z, Chen X, Jia G, Wu C, Zhao H, Xue B, Xiao L. 2013. Biological system responses to zearalenone mycotoxin exposure by integrated metabolomic studies. Journal of Agricultural \& Food Chemistry 61:11212-11221

Liu G, Wang C, Huang YX, Dong KH, Yang WZ, Zhang SL, Wang H. 2009. Effects of isovalerate on ruminal fermentation, urinary excretion of purine derivatives and digestibility in steers. Journal of Animal Physiology \& Animal Nutrition 93:716-725

Liu Q, Wang C, Pei CX, Li HY, Wang YX, Zhang SL, Zhang YL, He JP, Wang H, Yang WZ. 2014. Effects of isovalerate supplementation on microbial status and rumen enzyme profile in steers fed on corn stover based diet. Livestock Science 161:60-68

Liu Y, Wang W. 2016. Aflatoxin B1 impairs mitochondrial functions, activates ROS generation, induces apoptosis and involves Nrf2 signal pathway in primary broiler hepatocytes. Animal Science Journal 87:1490-1500

Lundstedt T, Trygg J, Holmes E. 2007. Chemometrics in metabonomics. Journal of Proteome Research 6:469-479

Mackle TR, Dwyer DA, Ingvartsen K, Chouinard Y, Ross DA, Bauman DE. 2000. Evaluation of Whole Blood and Plasma in the Interorgan Supply of Free Amino Acids for the Mammary Gland of Lactating Dairy Cows. Journal of Dairy Science 83:1300-1309

Maher AD, Rochfort SJ. 2014. Applications of NMR in dairy research. Metabolites 4: 131-141

Martin AF, Rabinowitz M, Blough R, Prior G, Zak R. 1977. Measurements of half-life of rat cardiac myosin heavy chain with leucyl-tRNA used as precursor pool. Journal of Biological Chemistry 252:3422-3429

Mccollum FT, Kim YK, Owens FN. 1987. Influence of supplemental four- and five-carbon volatile fatty acids on forage intake and utilization by steers. Journal of Animal Science 65:1674-1679

Nicholson JK, Wilson ID. 2003. understanding 'global' systems biology: metabonomics and the continuum of metabolism. Nature Reviews Drug Discovery 2:668-679

NRC (National Research Council). 2001. Nutrient Requirements of Dairy Cattle: Seventh Revised Edition, 2001. Washington, DC: The National Academies Press

Peer) reviewing PDF | (2018:12:33919:2:1:NEW 12 Feb 2020) 
485

486

487

488

489

490

491

492

493

494

495

496

497

498

499

500

501

502

503

504

505

506

507

508

509

510

511

512

513

514

515

O'Sullivan A, He X, McNiven E, Hinde K, Haggarty N, Lönnerdal B, Slupsky C. 2013. Metabolomic phenotyping validates the infant rhesus monkey as a model of human infant metabolism. Journal of Pediatric Gastroenterology \& Nutrition 56:355-363

Osorio JS, Trevisi E, Ji P, Drackley JK, Luchini D, Bertoni G, Loor JJ. 2014. Biomarkers of inflammation, metabolism, and oxidative stress in blood, liver, and milk reveal a better immunometabolic status in peripartal cows supplemented with Smartamine M or MetaSmart. Journal of Dairy Science 97:7437-7450

Otto ER, Yokoyama M, Ku PK, Ames NK, Trottier NL. 2003. Nitrogen balance and ileal amino acid digestibility in growing pigs fed diets reduced in protein concentration. Journal of Animal Science 81:1743-1753

Pier AC. 1992. Major biological consequences of aflatoxicosis in animal production. Journal of Animal Science $70: 3964-3967$

Pinotti L, Baldi A, Dell'Orto V. 2002. Comparative mammalian choline metabolism with emphasis on the highyielding dairy cow. Nutrition Research Reviews 15:315-332

Rodrigues I, Naehrer K. 2012. A Three-Year Survey on the Worldwide Occurrence of Mycotoxins in Feedstuffs and Feed. Toxins 4:663-675

Santos RR, Fink-Gremmels J. 2014. Mycotoxin syndrome in dairy cattle: characterisation and intervention results. World Mycotoxin Journal 7:357-366

Shen JS, Chai Z, Song LJ, Liu JX, Wu YM. 2012. Insertion depth of oral stomach tubes may affect the fermentation parameters of ruminal fluid collected in dairy cows. Journal of Dairy Science 95:5978-5984

Sun LW, Zhang HY, Wu L, Shu S, Xia C, Xu C, Zheng JS. 2014. (1)H-Nuclear magnetic resonance-based plasma metabolic profiling of dairy cows with clinical and subclinical ketosis. Journal of Dairy Science 97:15521562

Sundekilde UK, Poulsen NA, Larsen LB, Bertram HC. 2013. Nuclear magnetic resonance metabonomics reveals strong association between milk metabolites and somatic cell count in bovine milk. Journal of Dairy Science 96:290-299

Surai PF. 2002. Natural Antioxidants in Avian Nutrition and Reproduction. Nottingham University Press. 5-9

Wanapat M, Pimpa O. 1999. Effect of Ruminal NH3-N Levels on Ruminal Fermentation, Purine Derivatives, Digestibility and Rice Straw Intake in Swamp Buffaloes. Asian-Australasian Journal of Animal Sciences 12:904-907

Wang L, Lin Y, Bian Y, Liu L, Shao L, Lin L, Qu B, Zhao F, Gao X, Li Q. 2014. Leucyl-tRNA synthetase regulates lactation and cell proliferation via mTOR signaling in dairy cow mammary epithelial cells. International Journal of Molecular Sciences 15:5952-5969

Peer) reviewing PDF | (2018:12:33919:2:1:NEW 12 Feb 2020) 
516 Xiong JL, Wang YM, Nennich TD, Li Y, Liu JX. 2015. Transfer of dietary aflatoxin B1 to milk aflatoxin M1 and

517 effect of inclusion of adsorbent in the diet of dairy cows. Journal of Dairy Science 98:2545-2554

518 Xu CA, Wang GW, Li XB, Xie GH, Cheng X, Zhang HY. 2008. Metabolic characteristic of the liver of dairy cows

519 during ketosis based on comparative proteomics. Asian-Australasian Journal of Animal Sciences 21:1003-

$520 \quad 1010$

521 Zhang J, Yin Y, Shu X, Li T, Li F, Tan B, Wu Z, Wu G. 2013. Oral administration of MSG increases expression of 522 glutamate receptors and transporters in the gastrointestinal tract of young piglets. Amino Acids 45:1169-1177

523 Zhang L, Ye Y, An Y, Tian Y, Wang Y, Tang H. 2011. Systems responses of rats to aflatoxin b1 exposure revealed 524 with metabonomic changes in multiple biological matrices. Journal of Proteome Research 10:614-23 


\section{Table $\mathbf{1}$ (on next page)}

Ingredients and mycotoxin composition of diets ${ }^{1}$

Notes: ${ }^{1}$ Control group ( $0 \%$ of uncontaminated cottonseeds replaced in diet); $50 \%$ replacement group ( $50 \%$ of uncontaminated cottonseeds replaced with cottonseeds that were naturally contaminated with mycotoxins in diet) and $100 \%$ replacement group (100\% of uncontaminated cottonseeds replaced with cottonseeds that were naturally contaminated with mycotoxins in diet). ${ }^{2}$ Dried distillers grains with solubles. ${ }^{3} \mathrm{ppb}, \mu \mathrm{g} / \mathrm{kg}$; AFB1, aflatoxin B1; ZEA, zearalenone; DON, deoxynivalenol. ${ }^{4} \mathrm{ND}$, not detected. 
1 Table 1. Ingredients and mycotoxins composition of diets ${ }^{1}$.

\begin{tabular}{|c|c|}
\hline Item & $\% \mathrm{DM}$ \\
\hline \multicolumn{2}{|l|}{ Ingredient } \\
\hline Oats hay & 2.24 \\
\hline Corn silage & 45.57 \\
\hline Alfalfa hay & 8.07 \\
\hline Soybean meal & 4.86 \\
\hline DDGS $^{2}$ & 5.58 \\
\hline Corn meal & 11.88 \\
\hline Wheat bran & 2.24 \\
\hline Extruded soy flour & 0.56 \\
\hline Corn bran shotcrete & 4.59 \\
\hline Cottonseed & 4.48 \\
\hline Mineral meal & 0.22 \\
\hline Diamond XP & 0.13 \\
\hline $\mathrm{NaHCO} 3$ & 0.54 \\
\hline $\mathrm{NaCl}$ & 0.07 \\
\hline Premix & 1.12 \\
\hline Water & 7.84 \\
\hline \multicolumn{2}{|l|}{ Nutrients, \% of DM } \\
\hline Crude Protein & 17.65 \\
\hline Fat & 4.15 \\
\hline Non fiber carbohydrate & 39.5 \\
\hline Neutral detergent fiber & 29.49 \\
\hline $\mathrm{Ca}$ & 0.8 \\
\hline $\mathrm{P}$ & 0.48 \\
\hline Ash & 9.27 \\
\hline \multicolumn{2}{|l|}{ Energy (mcal/Kg) } \\
\hline Metabolic energy & 2.88 \\
\hline Net Energy & 1.67 \\
\hline \multicolumn{2}{|c|}{$\begin{array}{l}\text { Mycotoxins (50\% replacement), } \\
\text { ppb }^{3}\end{array}$} \\
\hline AFB1 & 20.08 \\
\hline ZEA & 85.13 \\
\hline DON & $\mathrm{ND}^{4}$ \\
\hline
\end{tabular}

2 Notes: ${ }^{1}$ Control group ( $0 \%$ of uncontaminated cottonseed replaced in diet); $50 \%$ replacement group ( $50 \%$ of the uncontaminated 3 cottonseed replaced with cottonseed contaminated with mycotoxins). ${ }^{2}$ Dried distillers grains with solubles. ${ }^{3} \mathrm{ppb}, \mu \mathrm{g} / \mathrm{kg} ; \mathrm{AFB} 1$, 4 aflatoxin B1; ZEA, zearalenone; DON, deoxynivalenol. ${ }^{4} \mathrm{ND}$, not detected. 


\section{Table 2 (on next page)}

Effects of cottonseed contaminated with mycotoxins ${ }^{1}$ on the serum biochemical, antioxidant, and immune indices of dairy cows

Notes: ${ }^{1}$ Control group (uncontaminated cottonseed), 50\% replacement group (50\% of the cottonseed replaced with cottonseed contaminated with mycotoxins), and 100\% replacement group ( $100 \%$ of the cottonseed replaced with cottonseed contaminated with mycotoxins). ${ }^{2}$ ALT, alanine aminotransferase ; AST, aspartate aminotransferase; GGT, $\gamma$-glutamyl transpeptidase; ALP, alkaline phosphatase; TP, total protein; ALB, albumin; GLOB, globulin; A/G, albumin/ globulin; UREA, urea; CR, creatinine; UA, uric acid; TBil, total bilirubin; DBil, directed bilirubin; IBiL, indirect bilirubin; TG, total triglyceride; TC, total cholesterol; GSH-PX, glutathione peroxidase ; MDA, malondialdehyde; T-AOC, total antioxidant capacity; SOD, superoxide Dismutase; IgG, immunoglobulin G; IgA, immunoglobulin A; IgM, immunoglobulin M. ${ }^{3}$ Probability associated with the F-test based on differences between treatments ${ }^{\text {ab }}$ Means in the same row with different superscripts are significantly different $(P<0.05)$ according to Tukey's test. 
2 Table 2. Effects of cottonseed contaminated with mycotoxins ${ }^{1}$ on the serum biochemical, antioxidant, and immune indices 3 of dairy cows.

\begin{tabular}{|c|c|c|c|c|c|}
\hline Item $^{2}$ & Control & $\mathbf{5 0} \%$ replacement & $100 \%$ replacement & SEM & $P$-value ${ }^{3}$ \\
\hline $\operatorname{ALT}(\mathrm{U} / \mathrm{L})$ & 29.75 & 29.75 & 29.86 & 1.05 & 0.99 \\
\hline AST (U/L) & 72.75 & 71.00 & 77.50 & 3.03 & 0.68 \\
\hline AST/ ALT & 2.52 & 2.41 & 2.62 & 0.11 & 0.78 \\
\hline GGT (U/L) & $43.09^{\mathrm{a}}$ & $29.30^{\mathrm{b}}$ & $34.45^{\mathrm{a}, \mathrm{b}}$ & 2.16 & 0.02 \\
\hline $\operatorname{ALP}(\mathrm{U} / \mathrm{L})$ & 90.31 & 67.61 & 71.19 & 12.36 & 0.74 \\
\hline $\mathrm{TP}(\mathrm{g} / \mathrm{L})$ & 73.96 & 73.53 & 73.53 & 0.97 & 0.98 \\
\hline $\operatorname{ALB}(\mathrm{g} / \mathrm{L})$ & 36.44 & 35.49 & 36.14 & 0.45 & 0.69 \\
\hline $\operatorname{GLOB}(\mathrm{g} / \mathrm{L})$ & 37.53 & 38.04 & 37.39 & 1.08 & 0.97 \\
\hline $\mathrm{A} / \mathrm{G}$ & 0.98 & 0.94 & 1.01 & 0.03 & 0.72 \\
\hline $\operatorname{UREA}(\mathrm{mmol} / \mathrm{ml})$ & 3.10 & 3.45 & 3.30 & 0.11 & 0.44 \\
\hline $\mathrm{CR}(\mu \mathrm{mol} / \mathrm{L})$ & 71.16 & 67.50 & 70.36 & 2.13 & 0.78 \\
\hline $\mathrm{UA}(\mu \mathrm{mol} / \mathrm{L})$ & 25.85 & 28.56 & 30.49 & 1.94 & 0.64 \\
\hline $\operatorname{TBil}(\mu \mathrm{mol} / \mathrm{L})$ & 11.05 & 9.82 & 9.82 & 0.53 & 0.46 \\
\hline $\operatorname{DBil}(\mu \mathrm{mol} / \mathrm{L})$ & 2.28 & 2.03 & 2.40 & 0.09 & 0.21 \\
\hline $\mathrm{IBiL}(\mu \mathrm{mol} / \mathrm{L})$ & 8.78 & 7.79 & 9.00 & 0.45 & 0.53 \\
\hline $\mathrm{TG}(\mathrm{mmol} / \mathrm{ml})$ & 0.05 & 0.05 & 0.06 & 0.004 & 0.74 \\
\hline $\mathrm{TC}(\mathrm{mmol} / \mathrm{ml})$ & 6.03 & 5.95 & 6.71 & 0.26 & 0.46 \\
\hline GSH-PX (U/ml) & 669.0 & 661.5 & 687.8 & 12.48 & 0.70 \\
\hline $\operatorname{MDA}(\mathrm{nmol} / \mathrm{ml})$ & 12.42 & 12.77 & 8.02 & 1.18 & 0.19 \\
\hline $\mathrm{SOD}(\mathrm{U} / \mathrm{ml})$ & 106.9 & 108.9 & 107.4 & 0.81 & 0.57 \\
\hline $\mathrm{SOD} / \mathrm{MDA}$ & 10.32 & 11.8 & 15.63 & 1.31 & 0.24 \\
\hline T-AOC(U/ml) & $2.40^{\mathrm{a}}$ & $2.39^{a}$ & $3.52^{\mathrm{b}}$ & 0.26 & 0.009 \\
\hline $\operatorname{IgG}(\mu \mathrm{g} / \mathrm{ml})$ & 13.67 & 18.75 & 13.75 & 2.13 & 0.56 \\
\hline $\operatorname{IgA}(\mathrm{ng} / \mathrm{ml})$ & 59.43 & 50.82 & 53.57 & 4.46 & 0.43 \\
\hline $\operatorname{IgM}(\mathrm{ng} / \mathrm{ml})$ & 22.40 & 23.42 & 22.30 & 1.95 & 0.93 \\
\hline
\end{tabular}

4 Notes: ${ }^{1}$ Control group (uncontaminated cottonseed), 50\% replacement group (50\% of the uncontaminated cottonseed replaced

5 with cottonseed contaminated with mycotoxins), and $100 \%$ replacement group ( $100 \%$ of the uncontaminated cottonseed replaced 6 with cottonseed contaminated with mycotoxins).

$7 \quad 2$ ALT, alanine aminotransferase; AST, aspartate aminotransferase; GGT, $\gamma$-glutamyl transpeptidase; ALP, alkaline phosphatase;

8 TP, total protein; ALB, albumin; GLOB, globulin; A/G, albumin/ globulin; UREA, urea; CR, creatinine; UA, uric acid; TBil, total

9 bilirubin; DBil, directed bilirubin; IBiL, indirect bilirubin; TG, total triglyceride; TC, total cholesterol; GSH-PX, glutathione

10 peroxidase; MDA, malondialdehyde; T-AOC, total antioxidant capacity; SOD, superoxide Dismutase; IgG, immunoglobulin G;

11 IgA, immunoglobulin A; IgM, immunoglobulin M.

$12{ }^{3}$ Probability associated with the F-test based on differences between treatments.

$13{ }^{\mathrm{ab}}$ Means in the same row with different superscripts are significantly different $(P<0.05)$ according to Tukey's test. 


\section{Table 3 (on next page)}

Effects of cottonseed contaminated with mycotoxins ${ }^{1}$ on volatile fatty acid concentrations in the cow rumen

Notes: ${ }^{1}$ Control group (uncontaminated cottonseed), 50\% replacement group (50\% of the cottonseed replaced with cottonseed contaminated with mycotoxins), and $100 \%$ replacement group ( $100 \%$ of the cottonseed replaced with cottonseed contaminated with mycotoxins). ${ }^{2}$

Probability associated with the F-test based on differences between treatments. ${ }^{\text {abc }}$ Means in the same row with different superscripts are significantly different $(P<0.05)$ according to Tukey's test. 
2 Table 3. Effects of cottonseed contaminated with mycotoxins ${ }^{1}$ on volatile fatty acid concentrations in the cow rumen.

\begin{tabular}{|c|c|c|c|c|c|}
\hline $\operatorname{Item}(\mathrm{mmol} / \mathrm{L})$ & Control & $\begin{array}{l}\mathbf{5 0} \% \\
\text { replacement }\end{array}$ & $\begin{array}{l}100 \% \\
\text { replacement }\end{array}$ & SEM & $P$-value \\
\hline Acetate & 65.55 & 62.72 & 60.78 & 1.08 & 0.19 \\
\hline Propoinate & 22.49 & 22.76 & 22.03 & 0.41 & 0.78 \\
\hline Acetate/Propoinate & 2.93 & 2.77 & 2.77 & 0.06 & 0.43 \\
\hline Isobutyrate & 0.66 & 0.72 & 0.75 & 0.02 & 0.27 \\
\hline Butyrate & 12.73 & 12.31 & 12.21 & 0.36 & 0.84 \\
\hline Isovalerate & $1.27^{\mathrm{a}}$ & $1.61^{\mathrm{b}}$ & $1.29 \mathrm{ac}$ & 0.05 & 0.008 \\
\hline Valerate & 1.39 & 1.51 & 1.31 & 0.06 & 0.21 \\
\hline
\end{tabular}

3 Notes: ${ }^{1}$ Control group (uncontaminated cottonseed), 50\% replacement group (50\% of the uncontaminated cottonseed replaced

4 with cottonseed contaminated with mycotoxins), and 100\% replacement group (100\% of the uncontaminated cottonseed replaced

5 with cottonseed contaminated with mycotoxins).

$6 \quad 2$ Probability associated with the F-test based on differences between treatments.

$7 \quad$ abc Means in the same row with different superscripts are significantly different $(P<0.05)$ according to Tukey's test. 


\section{Table 4 (on next page)}

OPLS-DA coefficients derived from the NMR spectra indicating the concentrations of metabolites present in plasma samples obtained from the three groups

(A) control, (B) $50 \%$ replacement group (50\% of the uncontaminated cottonseed replaced with cottonseed contaminated with mycotoxins) and (C) 100\% replacement group (100\% of the uncontaminated cottonseed replaced with cottonseed contaminated with mycotoxins).

${ }^{a}$ Correlation coefficients where positive and negative signs indicate positive and negative correlations between the concentrations, respectively. Correlation coefficients of $|r|>0.666,0.707$, or 0.755 were used as the cutoff values for significant differences based on the discrimination significance at the $P=0.05$ level, where $d f$ (degrees of freedom) $=7,6$, or 5 ; "-" indicates that the correlation coefficient $|r|$ was less than $0.666,0.707$, or 0.755 .

${ }^{\mathrm{b}}$ Multiplicity: s, singlet; $d$, doublet; $t$, triplet; q, quartet; dd, doublet of doublets; m, multiplet; br, broad resonance. 
2 Table 4. OPLS-DA coefficients derived from the NMR data of plasma metabolites obtained from (A) control, (B) 50\% 3 replacement group $(50 \%$ of the uncontaminated cottonseed replaced with cottonseed contaminated with mycotoxins) and 4 (C) $100 \%$ replacement group $(100 \%$ of the uncontaminated cottonseed replaced with cottonseed contaminated with 5 mycotoxins).

\begin{tabular}{|c|c|c|c|}
\hline \multirow[b]{2}{*}{ Metabolites ${ }^{b}$} & \multicolumn{3}{|c|}{$\mathrm{r}^{\mathrm{a}}$} \\
\hline & $\begin{array}{l}\text { A } v s . \mathrm{B} \\
(d f=7)\end{array}$ & $\begin{array}{l}\text { A } v s . \mathrm{C} \\
(d f=7)\end{array}$ & $\begin{array}{l}\text { B vs. C } \\
(d f=7)\end{array}$ \\
\hline Ala(Alanine): $1.48(\mathrm{~d})$ & - & -0.669 & 0.763 \\
\hline Lys(Lysine): 1.49(m), 1.74(m), 1.91(m) & 0.743 & - & 0.697 \\
\hline Gln(Glutamine $): 2.12(\mathrm{~m}), 2.42(\mathrm{~m})$ & - & - & 0.733 \\
\hline OAG(O-acetyl-glycoprotein): 2.13(s) & - & - & 0.668 \\
\hline Cit(Citrate): 2.54(d), 2.68(d) & - & -0.748 & 0.695 \\
\hline Cr(Creatine): $3.03(\mathrm{~s}), 3.93(\mathrm{~s})$ & - & - & 0.674 \\
\hline Gly(Glycine): 3.56(s) & - & - & 0.731 \\
\hline $\begin{array}{l}\text { Glucose: 3.42(t), 3.54(dd), 3.71(t), 3.73(m), 3.84(m), } \\
\text { 3.25(dd), 3.41(t), 3.46(m), 3.49(t), 3.90(dd), 4.65(d), } \\
5.23(\mathrm{~d})\end{array}$ & - & - & 0.768 \\
\hline
\end{tabular}
respectively. Correlation coefficients of $|\mathrm{r}|>0.666,0.707$, or 0.755 were used as the cutoff values for significant differences based on the discrimination significance at the $P=0.05$ level, where $d f$ (degrees of freedom) $=7$, 6, or 5; " ", indicates that the 9 correlation coefficient $|\mathrm{r}|$ was less than $0.666,0.707$, or 0.755.

10 bultiplicity: s, singlet; d, doublet; t, triplet; q, quartet; dd, doublet of doublets; m, multiplet; br, broad resonance. 


\section{Figure 1}

Effects of cottonseed contaminated with mycotoxins on the concentration of $\mathrm{NH}_{3}-\mathrm{N}$ (a) and total VFA (Volatile Fatty Acid) (b) in the cows rumen.

Notes: Control group $=$ uncontaminated cottonseed; $50 \%$ replacement group $=50 \%$ of the uncontaminated cottonseed was replaced with cottonseed contaminated with mycotoxins; and $100 \%$ replacement group $=100 \%$ of the uncontaminated cottonseed was replaced with cottonseed contaminated with mycotoxins 

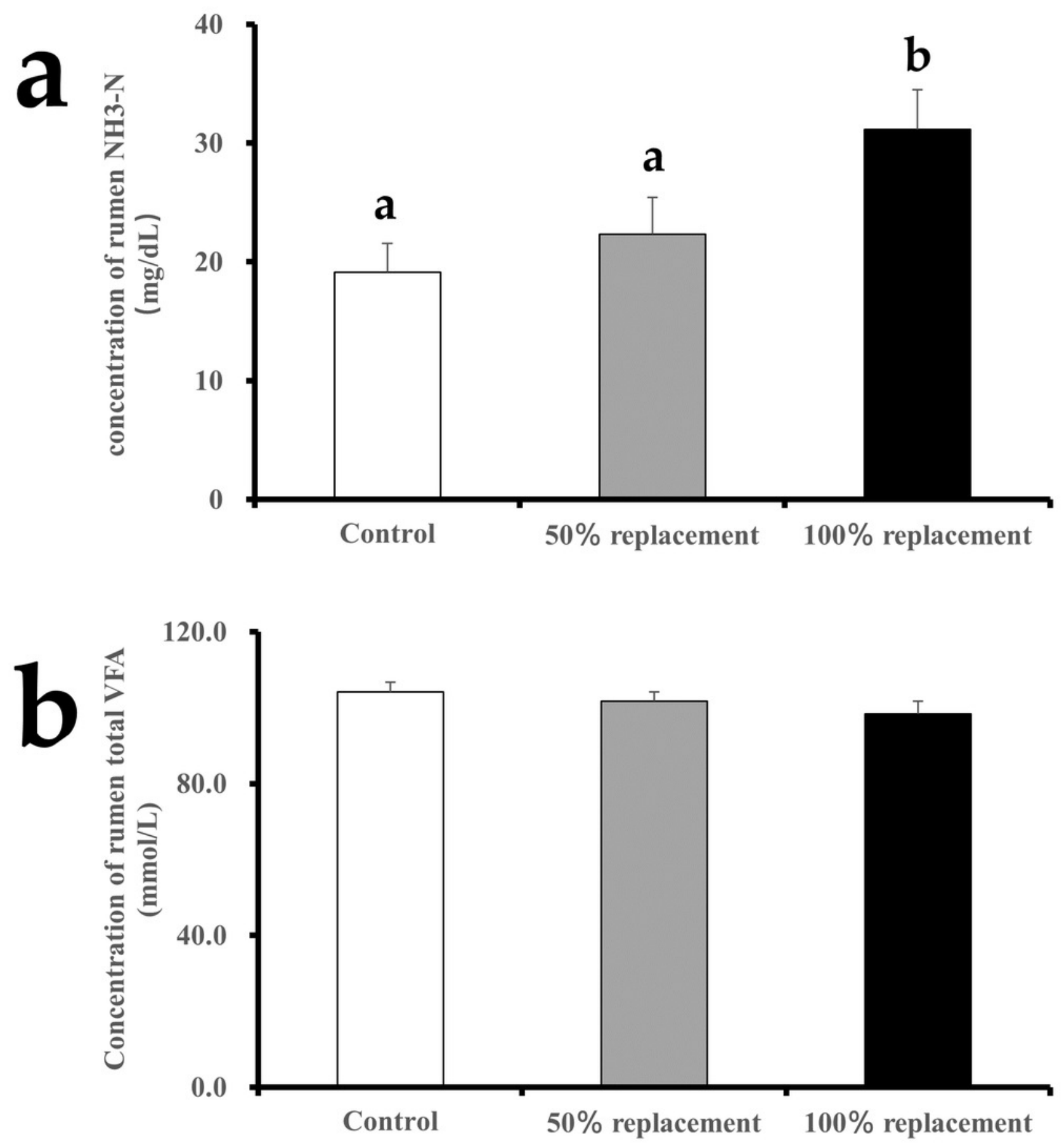
Figure 2

Representative $600 \mathrm{MHz}$ 1D NOESY 1H-NMR spectra (80.5-5.5 and $85.5-9.0)$ from cows plasma

(A) control group, (B) $50 \%$ replacement group (50\% of the uncontaminated cottonseed was replaced with cottonseed contaminated with mycotoxins), and (C) $100 \%$ replacement group (100 \% of the uncontaminated cottonseed was replaced with cottonseed contaminated with mycotoxins). The $85.5-9.0$ region was magnified 16 times relative to the corresponding 60.5-5.5 region for clarity. Abbreviations: Glu: Glutamate; NAG: N-acetyl glycoprotein signals; L1: LDL (Low Density Lipoprotein), $\mathrm{CH}_{3}-\left(\mathrm{CH}_{2}\right)$ n-; L2: VLDL (Very Low Density Lipoprotein), $\mathrm{CH}$ ${ }_{3}-\left(\mathrm{CH}_{2}\right) n-; \mathrm{L} 3: \mathrm{LDL}, \mathrm{CH}_{3}-\left(\mathrm{CH}_{2}\right) n-; \mathrm{L} 4: \mathrm{VLDL}, \mathrm{CH}_{3}-\left(\mathrm{CH}_{2}\right) n-; \mathrm{L} 5: \mathrm{VLDL},-\mathrm{CH}_{2} ; \mathrm{L6}$ : lipid, $-\mathrm{CH}_{2}-$ $\mathrm{CH}=\mathrm{CH}-$; L7: lipid, $-\mathrm{CH}_{2}-\mathrm{C}=0$; L8: lipid, $=\mathrm{CH}-\mathrm{CH}_{2}-\mathrm{CH}=$.

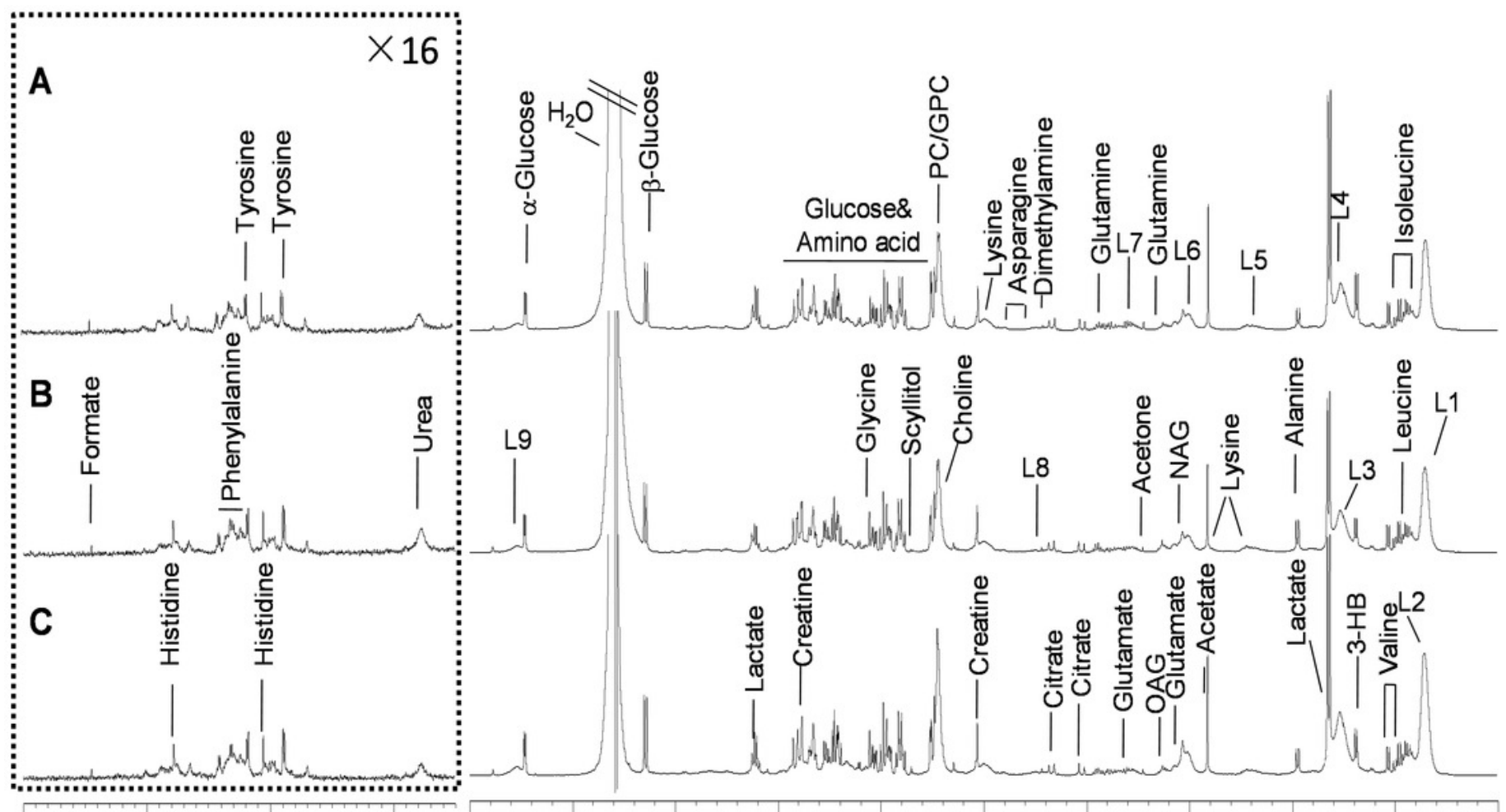


Figure 3

PCA plot based on the 1H NMR spectra for plasma obtained from different groups

control (I), black square; $50 \%$ replacement group ( $50 \%$ of the uncontaminated cottonseed was replaced with cottonseed contaminated with mycotoxins) (II), red spot; $100 \square$ replacement group ( $100 \%$ of the uncontaminated cottonseed was replaced with cottonseed contaminated with mycotoxins) (III), blue diamond.
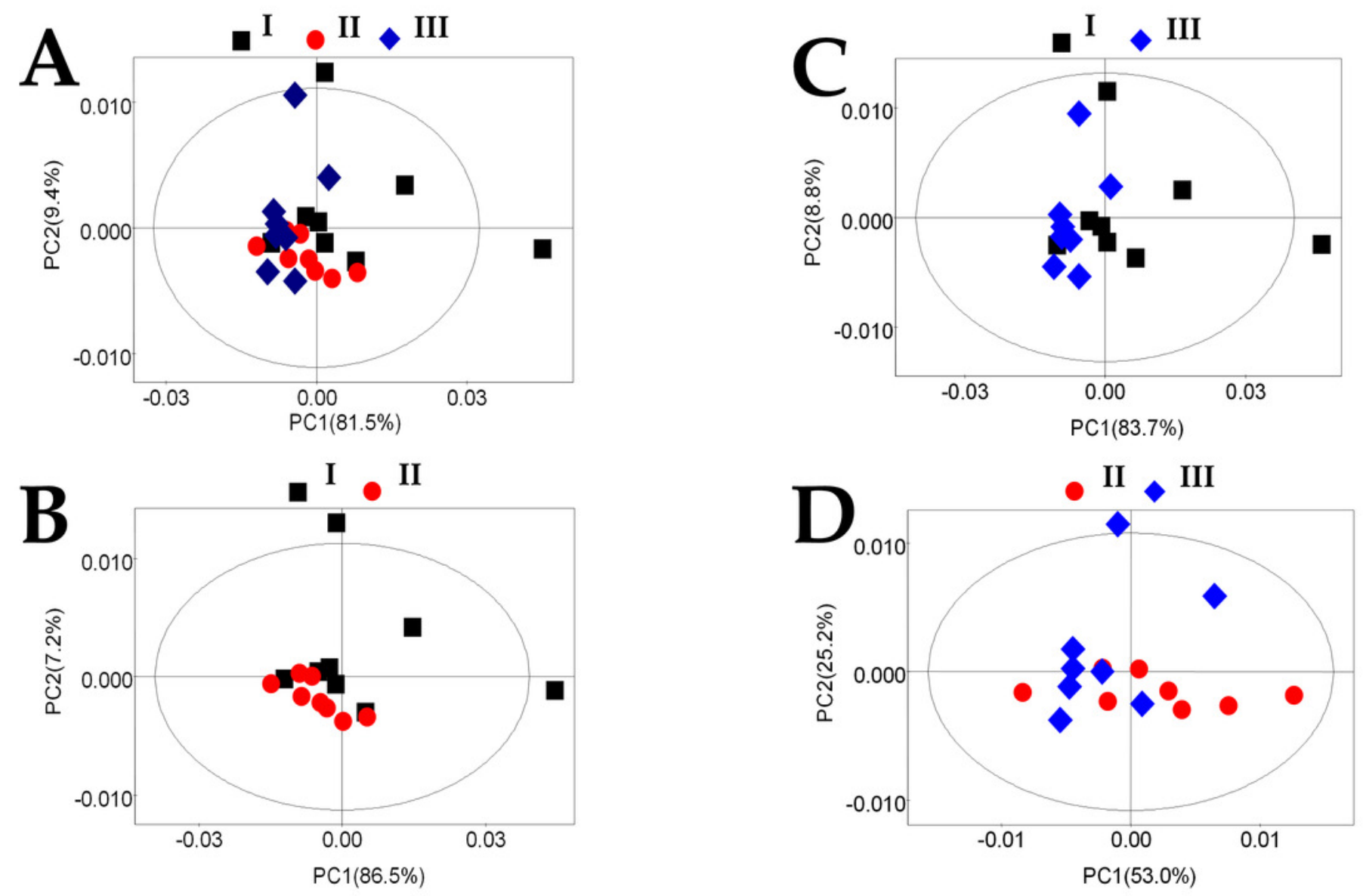


\section{Figure 4}

OPLS-DA score plots (left panel; A, D, and G) derived from 1 H NMR spectra for plasma and the corresponding coefficient loading plots (right panel; B, C, E, F, H, and I, in which, $\mathrm{B}, \mathrm{E}$ and $\mathrm{H}$ are images magnified 20 times)

control (I), black square; $50 \%$ replacement group ( $50 \%$ of the uncontaminated cottonseed was replaced with cottonseed contaminated with mycotoxins), (II), red spot; $100 \%$ replacement group ( $100 \%$ of the uncontaminated cottonseed was replaced with cottonseed contaminated with mycotoxins), (III), blue diamond. The color map shows the significant variations in metabolites between the two classes. Peaks in the positive direction indicate that metabolites were more abundant in the groups in the positive direction of the first principal component. Thus, metabolites that were more abundant in the three groups in the negative direction of the first primary component were shown as peaks in the negative direction. 

A
B
C
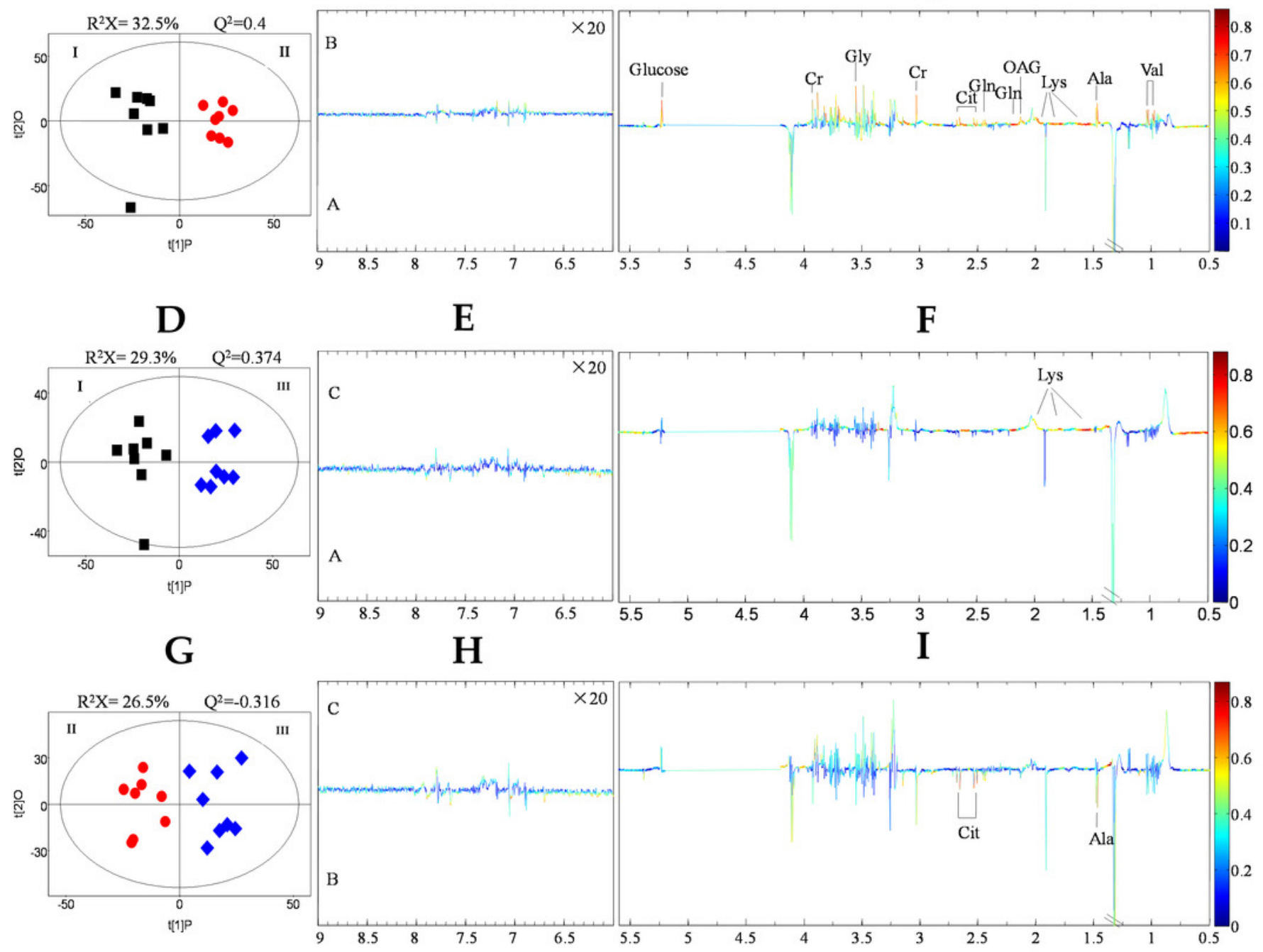


\section{Figure 5}

Metabolome view map showing the matched pathways according to the Pvaluesobtained from pathway enrichment analysis and the pathway impact valuesproduced by pathway topology analysis

a, Aminoacyl-tRNA biosynthesis; b, nitrogen metabolism; c, alanine, aspartate, and glutamate metabolism. The $x$-axis represents the pathway impact and the $y$-axis represents pathway enrichment. In the map, dots with larger sizes and darker colors represent higher pathway enrichment and higher pathway impact values, respectively. 


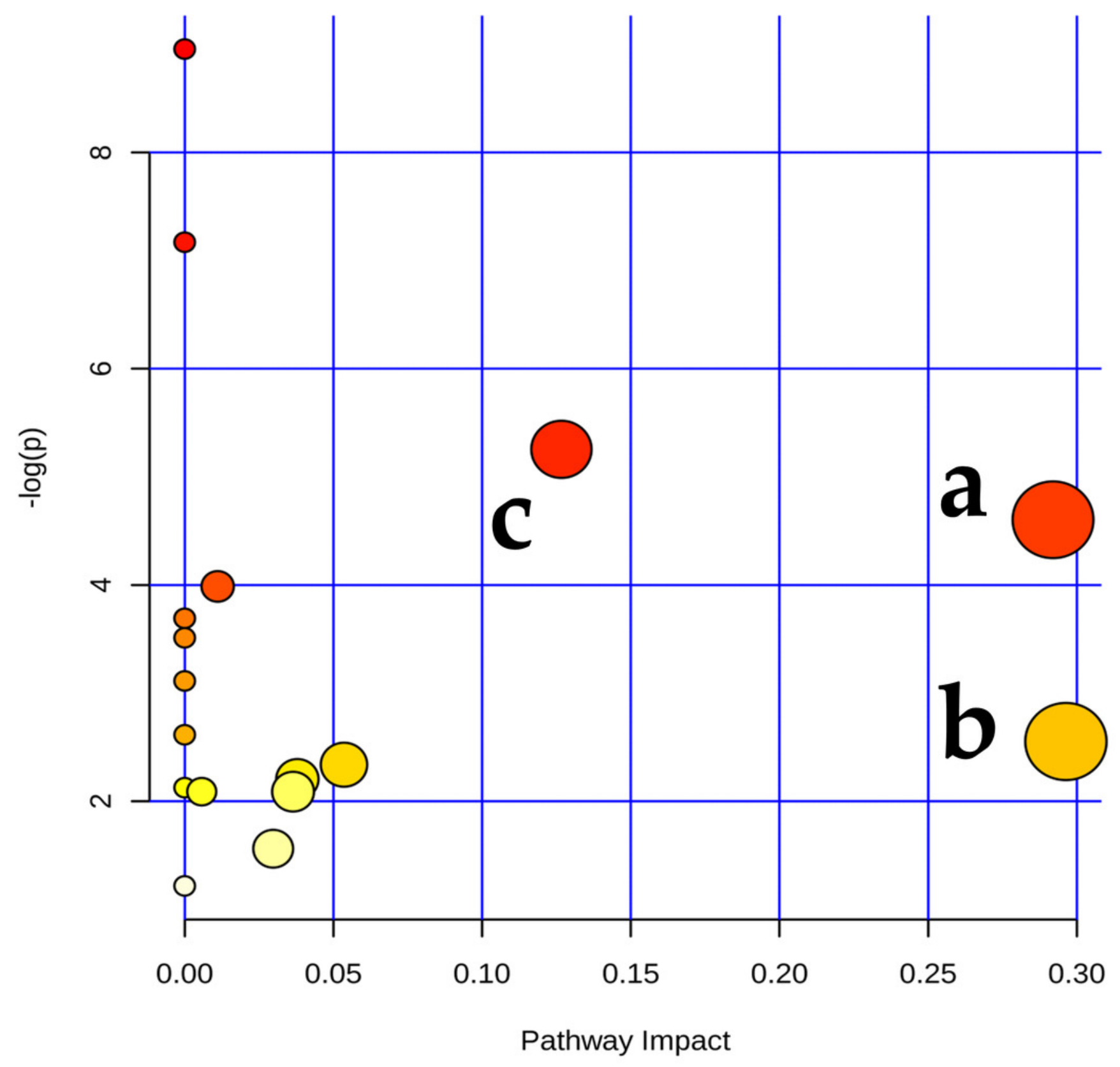

